\title{
USING EXERGY LOSS PROFILES AND ENTHALPY- TEMPERATURE PROFILES FOR THE EVALUATION OF THERMODYNAMIC EFFICIENCY IN DISTILLATION COLUMNS
}

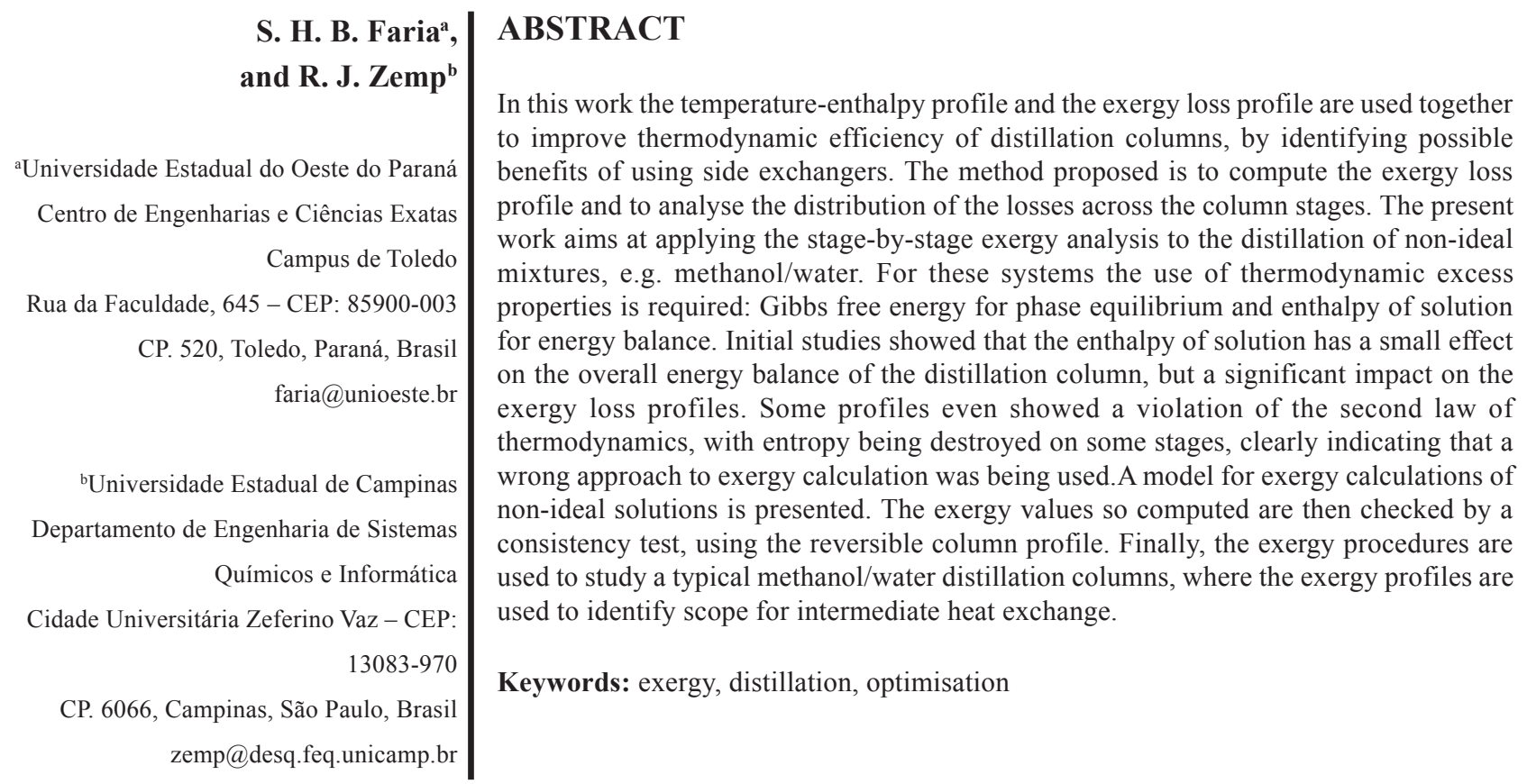

\section{NOMENCLATURE}

$\begin{array}{ll}\text { Ex } & \text { exergy, } \mathrm{kJ} / \mathrm{kmol} \\ \mathrm{H} & \text { enthalpy, } \mathrm{kJ} / \mathrm{kmol} \\ \mathrm{S} & \text { entropy, } \mathrm{kJ} / \mathrm{kmol} \mathrm{K} \\ \mathrm{T} & \text { temperature, } \mathrm{K} \\ \mathrm{Q} & \text { heat load, } \mathrm{kJ} / \mathrm{kmol}\end{array}$

\section{Greek symbols}

$\Delta \quad$ variation

\section{Subscripts}

util utility system of chemical plant

str streams

0 ambient

\section{INTRODUCTION}

Distillation is the most used separation operation in chemical and petrochemical industries. One disadvantage of distillation process is the large energy requirement (Fonyo et al, 2001). Thus, the motivation of this work was to analyse different configurations of distillation process, evaluating how much energy each configuration requires from the utility system. Furthermore, one can evaluate not only how much energy is required, but how energy is used by each configuration. If we are concerned only with the idea of minimising energy consumption for distillation columns, one could perform a stand- alone optimisation. Basically this optimisation will define the best combination of columns parameters like number of stages, reflux ration and feed thermal condition. However, in performing a stand-alone optimisation only the distillation column is analysed, and not its integration with the process. If one is interested in better use of energy, the possibility of heat integration between the column and the whole process should be considered. This can be done if available streams in the chemical plant that can exchange heat with the distillation column are identified. Then the optimisation of the columncan be carried out considering the possibility that part of the total column energy requirement could be supplied by process streams through intermediate heat exchangers. The idea of using intermediate heat exchangers is not new, Mah et al (1977) already analysed columns with intermediate heat exchangers, concluding that in some cases this alternative is very interesting. 
Many recent works also focused on the same subject. Dhole and Linhoff (1993) proposed an enthalpy-temperature profile similar to the grand composite curve of pinch analysis to identify scope for column improvement by feed pre-heating and intermediate heat exchange. These authors applied this procedure to a five-component separation, and concluded that this separation should be performed by a column with feed preheating, one side condenser and one side reboiler. Later, Zemp et al. (1997) proposed an approach based on the exergy loss distribution along the column to identify beneficial changes in a distillation column. The study of a multicomponent case (same as used by Dhole) lead to the conclusion that a column with only one side reboiler and feed preheating could perform the separation required, with the same exergy requirement as obtained by Dhole. The systematic procedure to optimise distillation columns based on exergy analysis, as presented by Zemp et al. (1997), identifies beneficial changes, like optimum feed stage, optimum feed thermal condition, as well as the possible benefits of using intermediate heat exchangers instead of changes in the thermal condition of the feed. Moussa (2001) compared both the enthalpy-temperature profile and exergy loss profile methodologies, and concluded that the best results are obtained when both are used simultaneously.

However, these optimisation methods have been tested only for the separation of ideal liquid mixtures. Faria (2003) showed that for some cases of separation of non-ideal mixtures, useful exergy loss profiles are not easily obtained.

The objective of the present work is to develop useful exergy loss profiles for separation of non-ideal systems, and to apply these profiles to optimise columns with intermediate heat exchangers. To accomplish this goal the separation of a highly non-ideal mixture (methanol/water) will be studied. The exergy loss profile and the enthalpy-temperature profile are used together to compute consistent exergy balances for the column. Finally, exergy loss profiles are used to evaluate possible benefits of using intermediate heat exchangers in this column.

\section{CONCEPTS}

The exergy loss profiles can identify beneficial changes in the column relative to exergy consumption, by analysing the distribution of the exergy losses along the column stages. A more uniform distribution leads to an overall lower exergy loss, and therefore a more efficient column. However, since changes in each stage are not feasible, a simplified analysis based on the distribution among column sections is used. If the values for the exergy losses in the rectifying and stripping section are close, then the total exergy consumption of the column is minimized (Zemp, 1994). This situation is illustrated in Fig. 1.

Figure 1(a) shows a profile obtained for a column with saturated liquid feed. For this case, exergy losses are larger in the stripping section and the column exergy requirement is $2933 \mathrm{~kJ} / \mathrm{kmol}$. When the feed is $20 \%$ vaporised (Fig. 1(b)) stream flow in the rectifying section increases and exergy losses redistribute between both sections of the column, with the loss profile showing a better "symmetry". The exergy consumption decreases slightly, indicating that this column should be operated with a feed preheat exchanger.
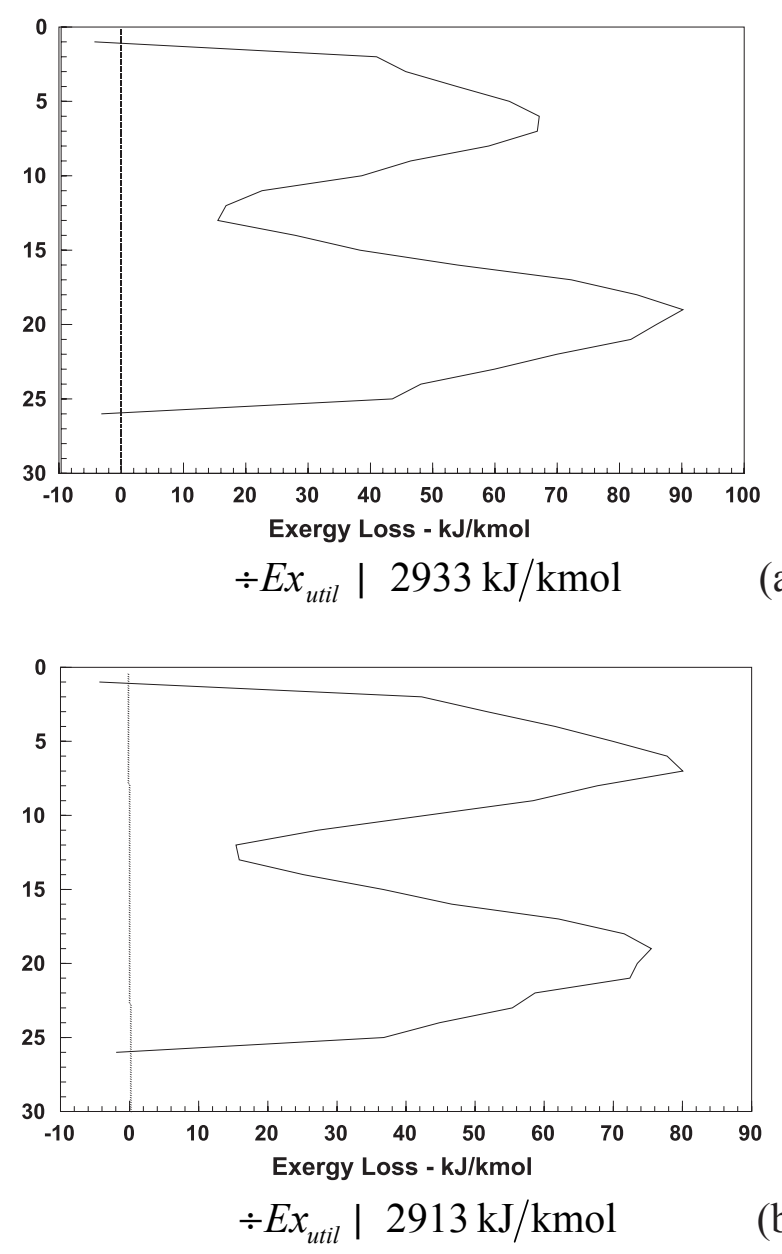

Figure 1. Exergy loss profiles for 0.5/0.5 nbutane/i-pentane split: (a) saturated liquid feed; (b) $20 \%$ vaporised feed.

This analysis can be extended to more complex situations. For example, consider the separation of a non-equimolar mixture, with feed at 
its bubble point. Figure 2(a) shows the exergy loss profile for this column. Clearly, a large exergy loss occurs in the rectifying section, whereas the stripping section has very small losses. According to the exergy loss profile methodology, liquid and vapour flows should be increased in the stripping section to increase its exergy loss, therefore distributing the overall exergy losses in a more uniform manner. One option is to use a subcooled column feed. However, although a better exergy loss distribution is achieved, the temperature difference between the feed stage and the feed stream leads to an undesired mixing loss at the feed stream, eventually increasing the overall exergy requirement (Fig. 2(b)).

Instead of subcooling the feed a side-condenser can be used (Fig. 3). The use of a side-condenser also increases vapour and liquid stream flows in stripping section of the column, making exergy loss distribution more uniform. For this case, there is no significant increase in feed stage exergy loss and the total exergy consumption is lower that the initial case (Fig. 3).

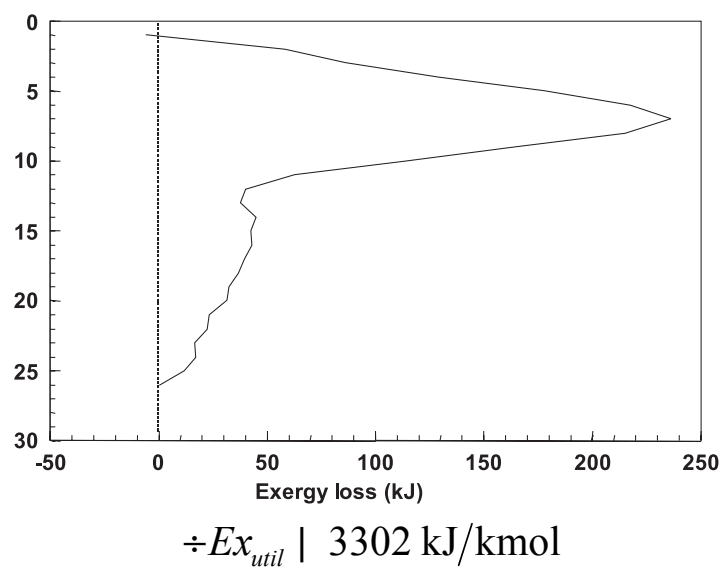

(a)

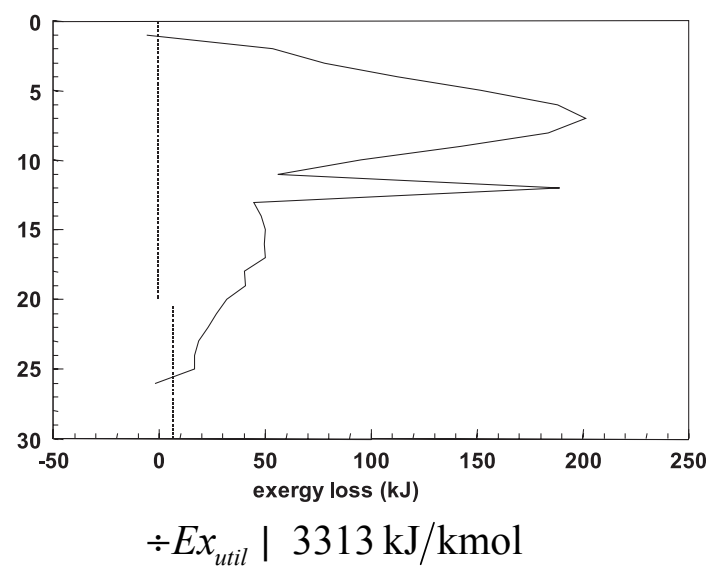

(b)

Figure 2. Exergy loss profiles for 0.25/0.75 nbutane/i-pentane split: (a) saturated liquid feed;

(b) subcooled feed.

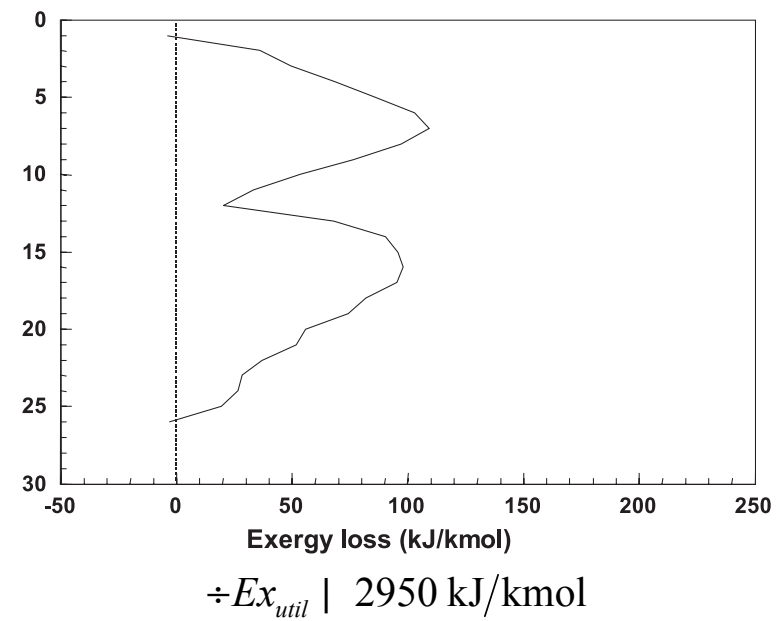

Figure 3. Exergy loss profiles for $0.25 / 0.75$ n-butane/i-pentane split, saturated liquid feed and side condenser in feed stage.

\section{NON-IDEAL SISTEMS}

So far, useful exergy loss profiles were obtained when dealing with near-ideal mixtures (usually mixtures in which chemical species are not very different, like hydrocarbons mixtures). However, how the exergy loss profile analysis would work for the separation of non-ideal mixtures was not known. The first attempt to obtain an exergy loss profile for a non-ideal mixture separation (methanol-water) is shown in Fig. 4. This column was simulated with a commercial chemical process simulator, and the data required for the exergy loss profile (steam flows, enthalpy and entropy) were extracted from the results file.

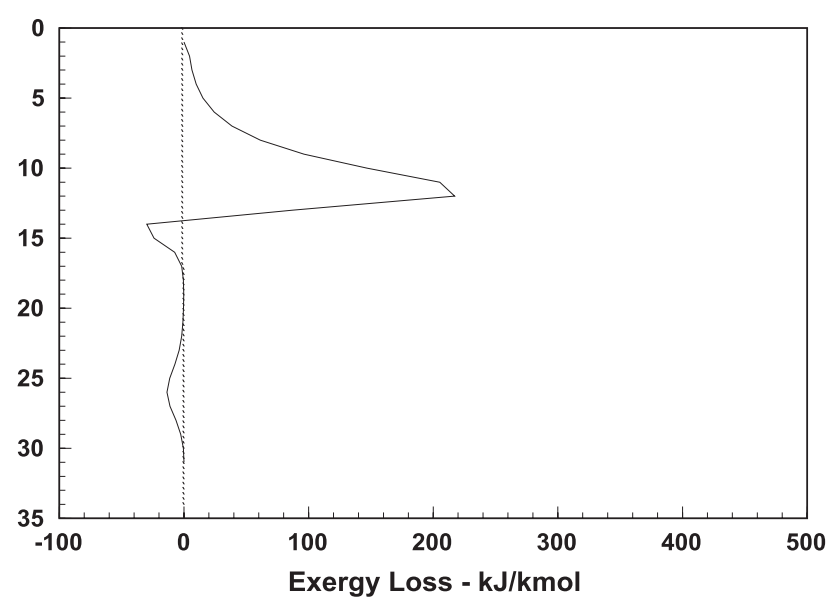

Figure 4. Exergy loss profile for $0.5 / 0.5$ methanol/water split, saturated vapour feed.

As can be seen in Fig. 4, some column stages present a negative exergy loss. This corresponds to a situation where entropy is being 
destroyed, not acceptable due to the Second Law. The main reason for this discrepancy is the way exergy is being computed. Unfortunately, the commercial simulators used to compute these balances do not allow access to their internal subroutines for the authors to verify how thermodynamic properties are being estimated. For example, it is not known if excess properties are being considered in procedure calculation, and those are expected to be necessary since non-ideal systems are being dealt with. Simulators usually allow the user to include excess enthalpy in calculation procedures, but not excess entropy, what makes a great difference in exergy balances. For near-ideal systems, like the hydrocarbon mixtures analyzed in previous work, computing exergy values raised no difficulty. This is due to the possibility of computing phase equilibria, enthalpy and exergy values using the same equation of state, e.g. Peng-Robinson. However, for highly non-ideal systems, like alcohol-water mixtures, conventional equations of state are no longer applicable, and one has to resort to excess property models.

Before developing a procedure to compute correct exergy values, a consistency check is proposed.

The change of exergy of a mixture undergoing a separation can be described by:

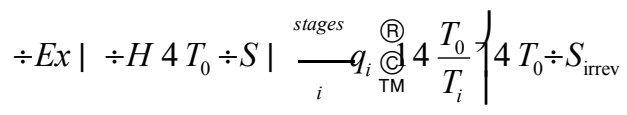

This equation shows that there is close relationship between the exergy change of the mixture ( $\ddot{A} E x)$ and the way heat is removed and/or transferred to the separator. Let us consider a reversible separator, so that $T_{0} \ddot{\mathrm{A}} S_{\text {irrev }}=0.0$. In this case the overall change of exergy of the streams entering and leaving the separator is equal to the sum of exergy flow from/to the heat reservoir. The change of exergy is a function of both enthalpy and entropy values, but the heat flow in or out of a separator is a function of the heat balance only. The reversible separator could therefore be used as a consistency test for the correct use of the excess properties for exergy calculation.

Once the reversible heat load has been computed, the exergy exchange between the

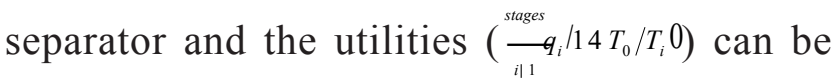

computed (Fig. 5). Table 1 shows a comparison between the exergy change of the streams and the exergy change of the utilities, for a set of ideal mixtures. There is a very good agreement between the exergy values, so that it can be concluded that the exergy consistency check is appropriate.

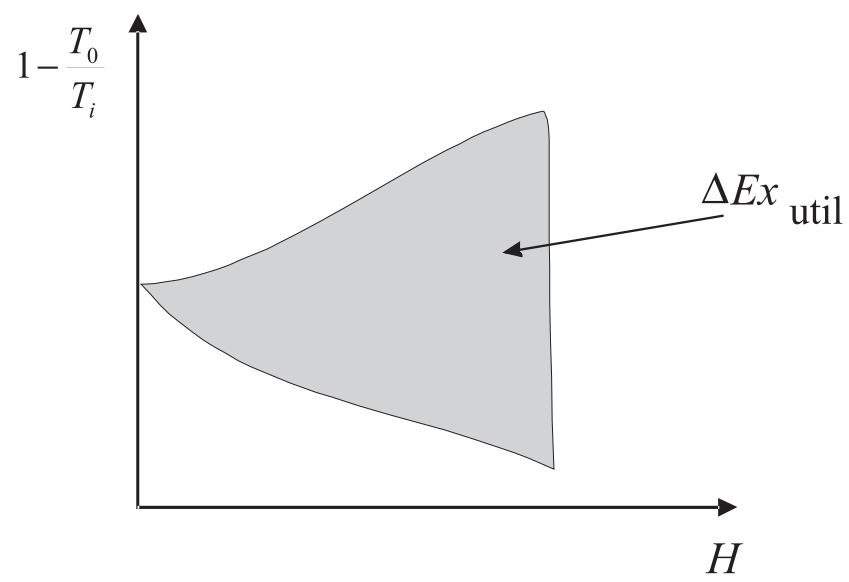

Figure 5. Reversible enthalpy-temperature profile

Table 1. Exergy change of the streams and exergy requirement for ideal systems.

\begin{tabular}{lccl}
\hline \multicolumn{1}{c}{ System } & $\begin{array}{c}\Delta E x_{\text {str }} \\
(\mathrm{kJ} / \mathrm{kmol})\end{array}$ & $\begin{array}{c}\Delta E x_{\text {util }} \\
(\mathrm{kJ} / \mathrm{kmol})\end{array}$ & $\begin{array}{c}\text { Difference } \\
(\%)\end{array}$ \\
\hline $\begin{array}{l}\text { n-butane/i- } \\
\text { pentane }\end{array}$ & 1650.45 & 1646.82 & 0.22 \\
$\begin{array}{l}\text { n-pentane/n- } \\
\text { hexane }\end{array}$ & 1606.60 & 1597.60 & 0.56 \\
$\begin{array}{l}\text { n-hexane/n- } \\
\text { heptane }\end{array}$ & 1650.45 & 1646.82 & 0.22 \\
\hline
\end{tabular}

However, when the same methodology is applied to non-ideal systems, a large deviation in exergy values is obtained (Tab. 2). These results confirm the suspicion that the enthalpy and entropy balances computed by commercial simulators might not be correct.

\section{ALTERNATIVE METHOD}

The authors decided to develop a thermodynamic framework for such solutions to be able to compute and check exergy values of nonideal systems, as follows. 
Table 2. Exergy change of the streams and exergy requirement for non-ideal systems.

\begin{tabular}{cccc}
\hline System & $\begin{array}{c}\Delta E x_{\text {str }} \\
(\mathrm{kJ} / \mathrm{kmol})\end{array}$ & $\begin{array}{c}\Delta E x_{\text {util }} \\
(\mathrm{kJ} / \mathrm{kmol})\end{array}$ & $\begin{array}{c}\text { Difference } \\
(\%)\end{array}$ \\
\hline methanol/water & 1750.04 & 1304.20 & 34.2 \\
\hline acetone/ethanol & 1561.91 & 1215.62 & 28.5 \\
\hline $\begin{array}{c}\text { water/acetic } \\
\text { acid }\end{array}$ & 1471.45 & 1859.92 & 20.9 \\
\hline
\end{tabular}

The enthalpy of a vapor stream can be computed from ideal gas heat capacities (considering ideal gas and ideal solution behavior), relative to a reference temperature $T_{\text {ref }}$ :

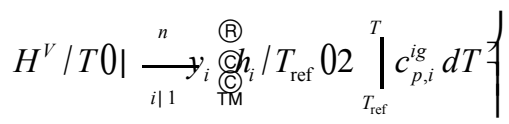

For the liquid phase, ideal gas enthalpy, enthalpy of vaporization and enthalpy of mixing (for non-ideal solutions) has to be considered.

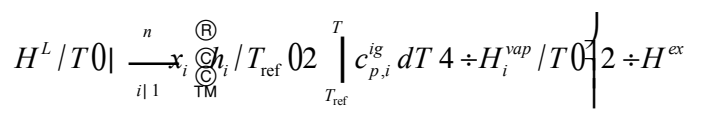

Similar equations are used to compute entropy values, with the addition of pressure and ideal mixing terms.

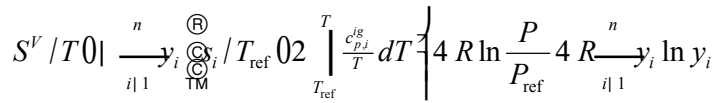

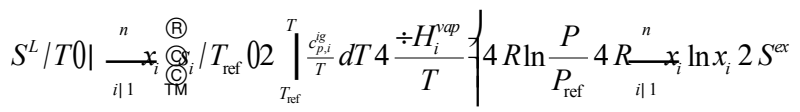

The above models were implemented as a computer program and used to compute the exergy value of the column streams. Then, Tab. 2 was rebuilt and the new results are shown in Tab. 3.

Table 3. Correct exergy values for no-ideal systems.

\begin{tabular}{cccc}
\hline System & $\begin{array}{c}\Delta \mathrm{Ex}_{\text {str }} \\
(\mathrm{kJ} / \mathrm{kmol})\end{array}$ & $\begin{array}{c}\Delta \mathrm{Ex}_{\mathrm{util}} \\
(\mathrm{kJ} / \mathrm{kmol})\end{array}$ & $\begin{array}{c}\text { Difference } \\
(\%)\end{array}$ \\
\hline $\begin{array}{c}\text { methanol/ } \\
\text { water }\end{array}$ & 1281.92 & 1352.19 & 5.2 \\
\hline $\begin{array}{c}\text { acetone/ } \\
\text { ethanol }\end{array}$ & 1239.96 & 1215.62 & 2.0 \\
\hline $\begin{array}{c}\text { water/acetic } \\
\text { acid }\end{array}$ & 1755.92 & 1846.95 & 4.9 \\
\hline
\end{tabular}

Comparing the new results it can now be seen that the $\mathrm{D} E x_{\text {str }}$ and $\mathrm{D} E x_{\text {util }}$ values are very close. The conclusion is that since we consider excess properties in calculation procedures, the exergy balances became more consistent. Consequently the new exergy profiles that could be generated by these consistent balances should be very different from the profile shown in Fig. 4. In order to confirm this, the exergy loss profile was rebuilt and the new profile is shown in Fig. 6.

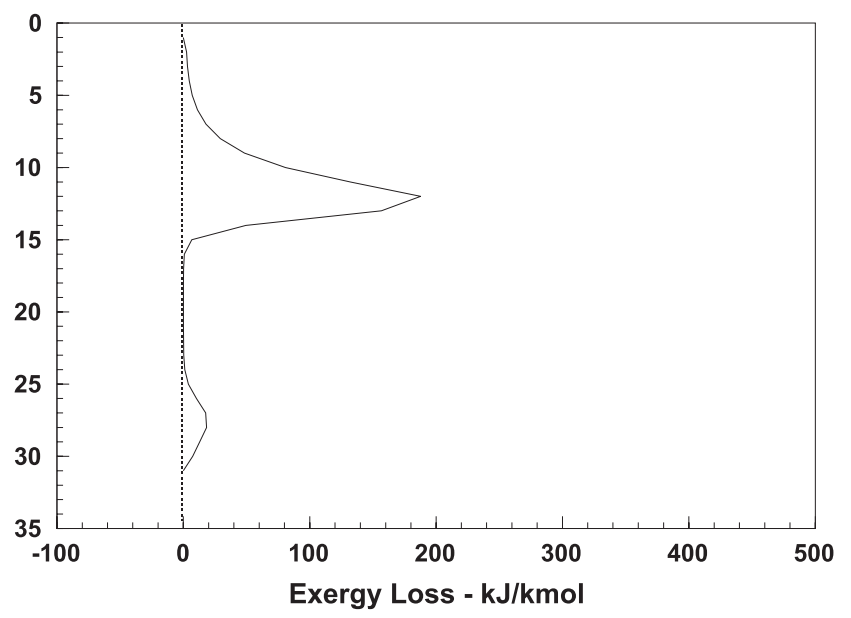

Figure 6. Exergy loss profile for $0.5 / 0.5$ methanol/water split, saturated vapour feed.

The new profile, generated by consistent exergy balances, does not show any negative exergy loss. This profile represents driving force distribution in the column and can be used to identify beneficial changes in column layout. Exergy loss profiles are used below to evaluate intermediate heat exchanges viability.

\section{RESULTS AND DISCUSSION}

The next step was to apply the new procedure to the analysis of a non-ideal system separation, e.g. a methanol/water column with 26 stages. Figure 7 shows the exergy loss profile obtained for this separation. The profile shows a large exergy loss in the stripping section, and a small exergy loss in the rectifying section. Overall, the exergy loss is very poorly distributed along the column. 


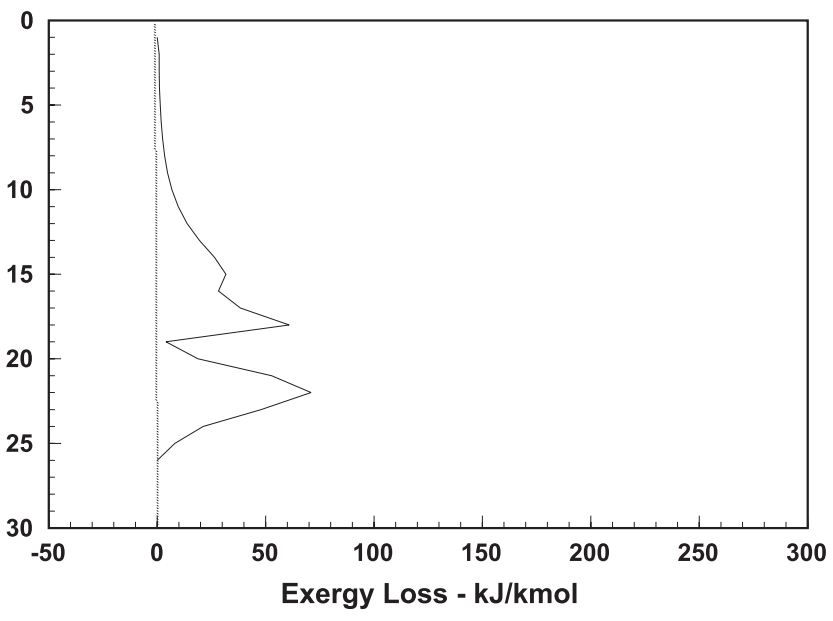

Figure 7. Exergy loss profile for $0.25 / 0.75$ methanol/water split

One way to redistribute exergy losses and increase the thermodynamic efficiency of this column is to use a side-reboiler in the stripping section, as it is expected that this would increase the internal flows in the top section of the column, leading to a more balance exergy use.

Figure 8 shows the improved column, with a side-reboiler at stage 18 (heat load of $10000 \mathrm{~kJ} / \mathrm{kmol}$ of feed). Clearly, the exergy loss profile is much more balanced, and the exergy requirement has decreased by $399 \mathrm{~kJ} / \mathrm{kmol}$, a decrease of around $20 \%$.

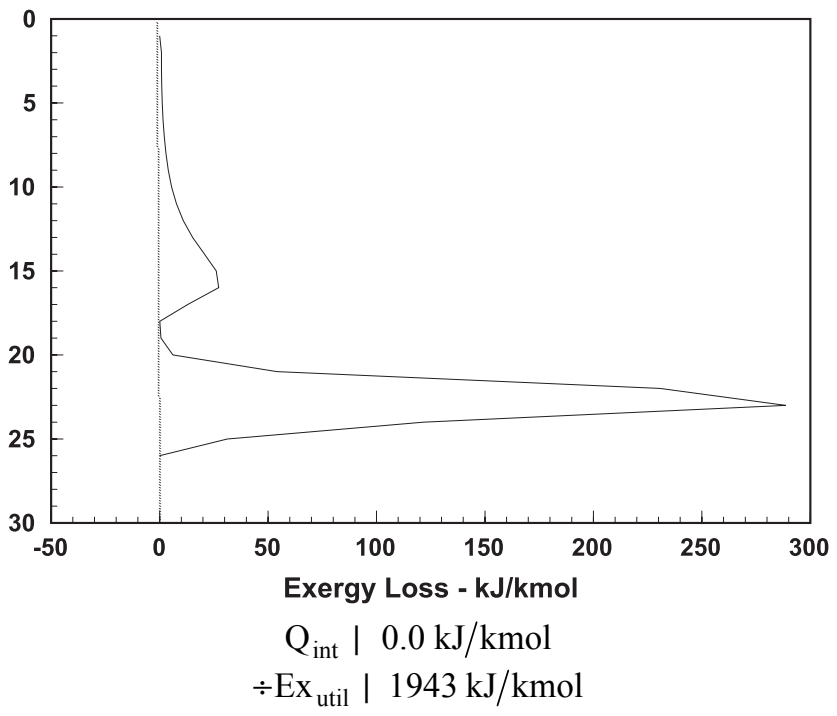

Figure 7. Exergy loss profile for $0.25 / 0.75$ methanol/water split.

One way to redistribute exergy losses and increase the thermodynamic efficiency of this column is to use a side-reboiler in the stripping section, as it is expected that this would increase the internal flows in the top section of the column, leading to a more balance exergy use.
Figure 8 shows the improved column, with a side-reboiler at stage 18 (heat load of $10000 \mathrm{~kJ} / \mathrm{kmol}$ of feed). Clearly, the exergy loss profile is much more balanced, and the exergy requirement has decreased by $399 \mathrm{~kJ} / \mathrm{kmol}$, a decrease of around $20 \%$.

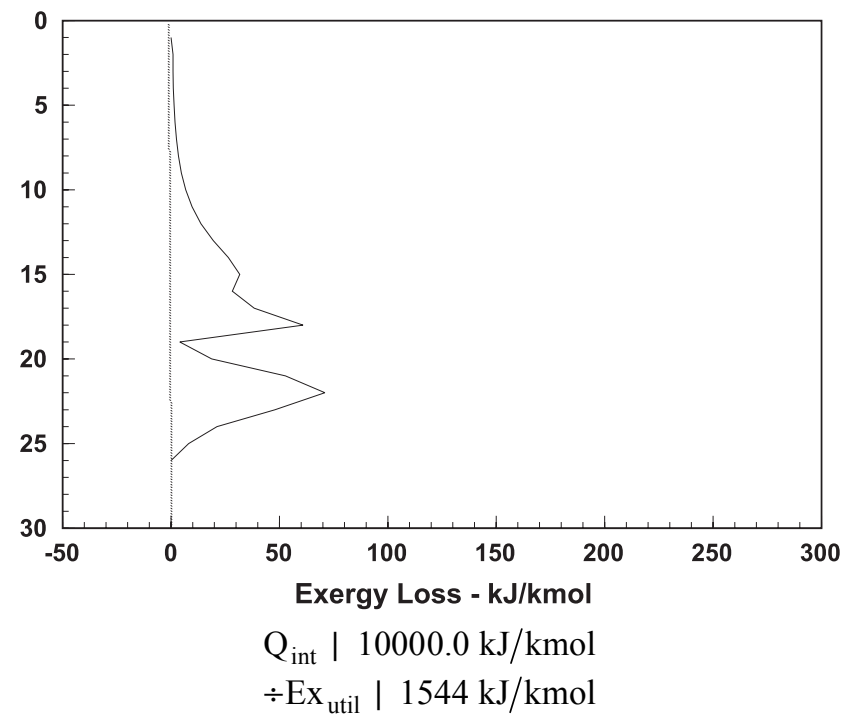

Figure 8. Exergy loss profile for $0.25 / 0.75$ methanol/water split, with side-reboiler.

\section{CONCLUSIONS}

In this work the concepts of exergy loss profiles and enthalpy-temperature profiles have been considered as a tool for improving thermodynamic efficiency of distillation columns.

Compared to traditional methods of analysis of column performance, the driving force distribution analysis based on exergy is very simple, and can be applied to a distillation column regardless of the complexity caused by large number of components, number of trays, number of feeds and sidestreams, and use of intermediate heating or cooling. The only requirement is the

computation of consistent physical properties.

However, for its use in the analysis of the distillation of non-ideal mixtures proper care has to be taken to correctly compute exergy values. The consideration of excess properties is of fundamental importance in this case, and some quite common simplifications can lead to very erroneous results.

The complete thermodynamic framework required to compute exergy values has been implemented. Additionally a consistency test based on the reversible column model has been proposed. The results showed a very good agreement with the computed values, indicating the exergy procedure 
to be correct. This procedure is of great use for thermodynamic analysis of separation processes.

The exergy loss profiles obtained by these balances are useful in identifying beneficial changes in column layout from the point of view of exergy consumption.

\section{REFERENCES}

Dhole, V. R., 1991, Distillation column integration and overall design of subambient plants, Doctoral Thesis, UMIST, UK.

Dhole, V. R., Linnhoff, B., 1993, Distillation columns targets, Computers and Chemical Engineering, Vol. 17, pp. 549-560.

Faria, S. H. B, 2003, Estudo energético de colunas de destilação através de análise exergética - Sistemas não ideais, Doctoral Thesis, UNICAMP, Campinas, SP. (in Portuguese)

Fonyo, Z., Rév, E., Emtir, M., Szitkai, Z., Mizsee P., 2001, Energy savings of integrated and coupled distillation systems, Comp. Eng., Vol. 25, pp. 119-140.

Mah, R. S. H., Nicholas Jr., J. J., Wodnik, R. B., 1977, Distillation with secondary reflux and vaporization: A comparative evaluation, AIChE Journal, Vol. 23, No. 5, pp. 651-658.

Moussa, L. S., 2001, Análise termodinâmica de colunas de destilação visando à otimização energética, Masters Dissertation, UNICAMP, Campinas, SP. (in Portuguese)

Zemp, R. J., 1994, Thermodynamic analysis of separation systems, Doctoral Thesis, UMIST, UK.

Zemp, R. J., Faria, S. H. B., Maia, M. L. O., 1997, Driving force distribution and exergy loss in the thermodynamic analysis of distillation columns, Computers and Chemical Engineering, Vol. 21, pp. S523-S528. 